\title{
INSECT PSYCHOLOGY.
}

BY JUSTUS WATSON FOLSOM, CHAMPAIGN, ILL.

This article is intended to summarize, without much argument, some of the best approved views of the present upon this difficult subject.

Insects are eminently instinctive; though their automatic behavior is often so remarkably successful as to appear rational, instead of purely instinctive.

Instinct, as distinguished from reason, attains adaptive ends without prevision and without experience. For example, a butterfly selects a particular species of plant upon which to lay her eggs. Caterpillars of the same species construct the same kind of nest, though so isolated from one another as to exclude the possibility of imitation. Every caterpillar that pupates accomplishes the intricate process after the manner of its kind, without the aid of experience.

Instinctive actions all belong to the reflex type,- they consist of coördinated reflex acts. A complex instinctive action is a chain, each link of which is a simple reflex act. In fact, no sharp line can be drawn between reflexive and instinctive actions.

Reflex acts, the elements from which instinctive actions are compounded, are the inevitable responses of particular organs to appropriate stimuli, and involve no volition. The presence of an organ normally implies the ability to use it. The newly born butterfly needs no practice preliminary to flight. The process of stinging is entirely reflex; a decapitated bee retains the power to sting, directing its weapon toward any part of the body that is irritated, and a freshly emerged bee, without any practice, performs the stinging movements with the greatest precision.

As Whitman observes, the roots of instincts are to be sought in the constitutional activities of protoplasm.

The ostensible rationality of behavior among insects, as was said, often leads one to attribute intelligence to them, even when there is no evidence of its existence. As an illustration, many plant-eating beetles, when disturbed, habitually drop to the ground and may escape detection by remaining immovable. We cannot, however, believe that these insects "feign death" with any consciousness of the benefit thus to be derived. This act, widespread among animals in general, is instinctive, or reflex, as Whitman maintains, being, at the same time, one of the simplest, most advantageous and deeply seated of all instinctive performances.

Take the many cases where an insect lays her eggs upon only one species of plant. The philenor butterfly hunts out Aristolochia, which she cannot taste, in order to serve larvae, of whose existence she can have no fore knowledge. Ovipo- 
sition is here an instinctive act, not performed until it is evoked by some sort of stimulus - perhaps an olfactory one - from a particular kind of plant.

Some determinate sensory stimulus is, indeed, the necessary incentive to any reflex act. The first movements of a larva within the egg-shell are doubtless due to a sensation, probably one of temperature. Simple contact with the egg-shell is probably sufficient to stimulate the jaws to work, and the caterpillar eats its way out; yet it cannot foresee that its biting is to result in its liberation. Nor, later on, when voraciously devouring leaves, can the caterpillar be supposed to know that it is storing up a reserve supply of food for the distant period of pupation and the subsequent imaginal stage. The ends of these reflex actions are proximate and not ultimate, except from the standpoint of higher intelligence.

An action can be regarded as purely instinctive in its initial performance only, because every subsequent performance may have been modified by experience; in other words, habits may have been forming and fixing, so that the results of instinct become blended with those of experience. Thus the first flight of a dragon-fly is instinctive and erratic, but later efforts, aided by experience, are well under control.

When once shaped by experience, reflex or instinctive actions tend to become intense habits. Thus, certain caterpillars, having eaten all the available leaves of a special kind, will almost invariably die rather than adopt a new food plant, whereas larvae of the same species will eat a strange plant if it is offered to them at birth. An act is strengthened in each repetition by the influence of habit, to the increasing exclusion of other possible modes of action. Many a caterpillar, having eaten its way out of the egg-shell, does not stop eating, but consumes the remainder of the shell, - a reflex act, started by a stimulus of contact against the jaws and continued until the cessation of the stimulus, unless some stronger stimulus should intervene. It has been said that the larva eats the remains of the shell because they might betray its presence to its enemies. Whether this is true or not, to assume conscious foresight of such a result on the part of an inexperienced caterpillar is worse than unnecessary.

With insects, as with other animals, many instincts are transitory; even when partially fixed by habit, they are replaceable by stronger instincts. Thus the gregarious habit of larvae is finally overpowered by a propensity to wander, which does not mature, however, until the approach of the transformation period. The reproductive instinct is another of those impulses that do not ripen until a certain age in the individual.

Broadly speaking, instinctive actions lack individuality,- are performed in the same way by every individual of the species. The solitary wasps of the same species are remarkably consistent in architecture, in the selection of a special kind of prey, the way in which they sting it, carry it to the nest and dispose of it; all these 
operations, moreover, are performed in a sequence that is characteristic of the species. Examples of this so-called inflexibility of instinct are so omnipresent that insect behavior as a whole is admitted to be instinctive, or automatic. Insects are capable of an immense number of reflex impulses, ready to act singly or in intricate correlation, upon the requisite stimuli from the environment.

To normal conditions of the environment, the behavior of an insect is accurately adjusted; in the face of abnormal circumstances, however, demanding the exercise of judgment, most insects are helpless. The specialization to one kind of food, though usually advantageous, is fatal if the supply becomes insufficient and the larva is unable to adopt another food. A species of Sphex habitually drags its grasshopper victim by one antenna. Fabre cut off both antennae and then found that the Sphex, after vain efforts to secure its customary hold, abandoned the prey. Under such unaccustomed conditions, insects often show a surprising stupidity, capable as they are amid ordinary circumstances.

Notwithstanding such examples, the common assertion that instincts are "blind," or inflexible, is incorrect. Instinctive acts are not mechanically invariable, though their variations are so inconspicuous as frequently to escape casual observation. A precise observer may detect individual variations in the performance of any instinctive act, - variations which are analogous to those of structure.

To take extreme examples, the Peckhams found that an occasional queen of Polistes fusca would occupy a comb of the previous year, in place of building a new one. They observed also that one Ammophila, in order to pound down the earth over her nest, actually used a stone, held between the mandibles.

While most of the variations that one encounters are small and, in a sense, accidental, or purposeless, such novel departures as those of the Polistes or the Aмmophila denote adaptability.

Even the despotic power of habit may be overborne by individual adaptability. Among caterpillars that have exhausted their customary food, there are often a few that will adopt a new food-plant and survive, leaving their more conservative fellows to starve.

As Darwin himself held, the doctrine of natural selection is applicable to instincts as well as to structures. All reflex acts are to some extent variable. Disadvantageous reflexes or combinations of reflexes eliminate themselves, while advantageous ones persist and accumulate.

Indeed, structures and instincts must frequently have evolved hand in hand. The remarkable protective resemblance of the Kallima butterfly would be useless, did not the insect instinctively rest among dead leaves of the appropriate kind.

Though manifestly dominant, instinct alone fails to account for all insect behavior. The ability of an insect to profit by experience indicates some degree of intelligence. 
If we take, as one criterion of intelligence, the power to choose between alternatives, then insects are more intelligent than is generally admitted. The control of locomotion, the selection of prey, and the avoidance of enemies, as results of experience, indicate powers of discrimination. Honey bees sometimes utilize varnish, pitch, and other substances as cements, instead of laboriously manufacturing their propolis from the exudations of plants.

Again, an ant, having discovered food, returns and leads its companions to the prize; or one ant may summon others to its assistance. Here the power of intercommunication, conceded to exist among the social Hymenoptera, implies some amount of intelligence.

If instinct is blind, or mechanical, with no adjustment of means to ends, then a pronounced individuality of action must signify something more than instinct, as in the case of the Ammophila.

From the standpoint of pure instinct, indeed, much of the behavior of the social Hymenoptera is inexplicable. The activities of the harvesting ants, the military or the slave-holding species, are of such nature that the possibility of education by experience and instruction is strong, to say the least. In fact, Forel and others maintain that a young ant is actually trained to its domestic duties by its older companions and that the well-known discrimination between friends and foes is also a matter of education.

However intelligent the social Hymenoptera may be in their way, they show no signs of the power of abstract reasoning. Even ants, according to the experiments of Lubbock, display profound stupidity in the face of novel emergencies when they might extricate themselves by abstract reasoning of the simplest kind. The thoughts of an ant or a bee seem to be limited to simple associations of concrete things.

There are two leading theories as to the origin of instinct. Lamarck, Romanes, and their followers have regarded instinct as inherited habit; have supposed that instincts have originated by the relegation to the reflex type of actions that at first were rational, and that instincts represent the accumulated results of ancestral experience. This habit theory, however, has little to support it, and assumes the inheritance of acquired characters - which has not been proved.

The selection theory of Darwin, Weismann, Morgan, and others has much in its favor. It regards reflex acts as primitive, as the raw material from which natural selection, as the chief factor, has effected those combinations that are termed instincts.

Finally, there is a growing tendency to regard instinct as the basis of intelligence. With the advent of consciousness, involving memory and choice, instinct ceases to be blind and reason begins. 

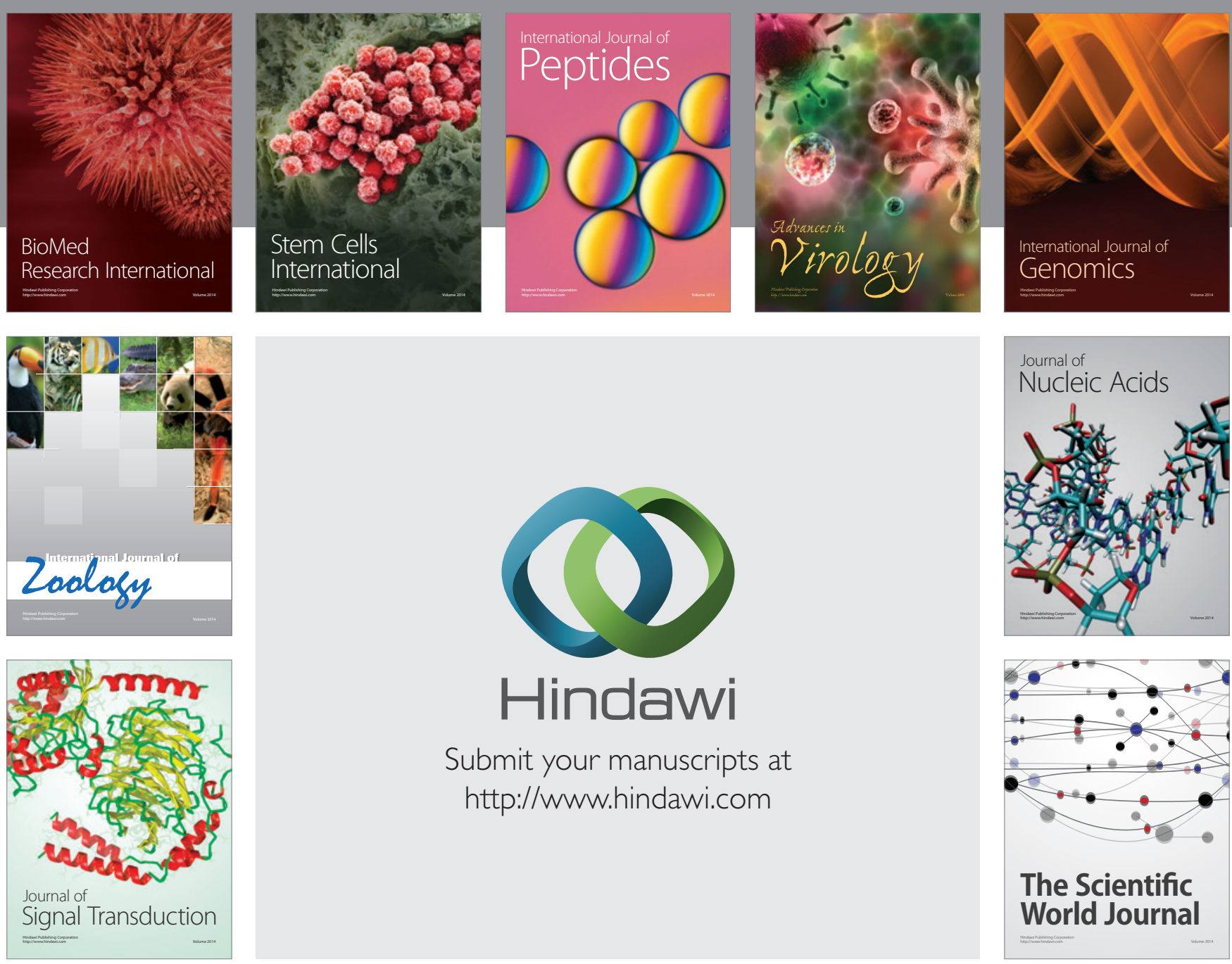

Submit your manuscripts at

http://www.hindawi.com
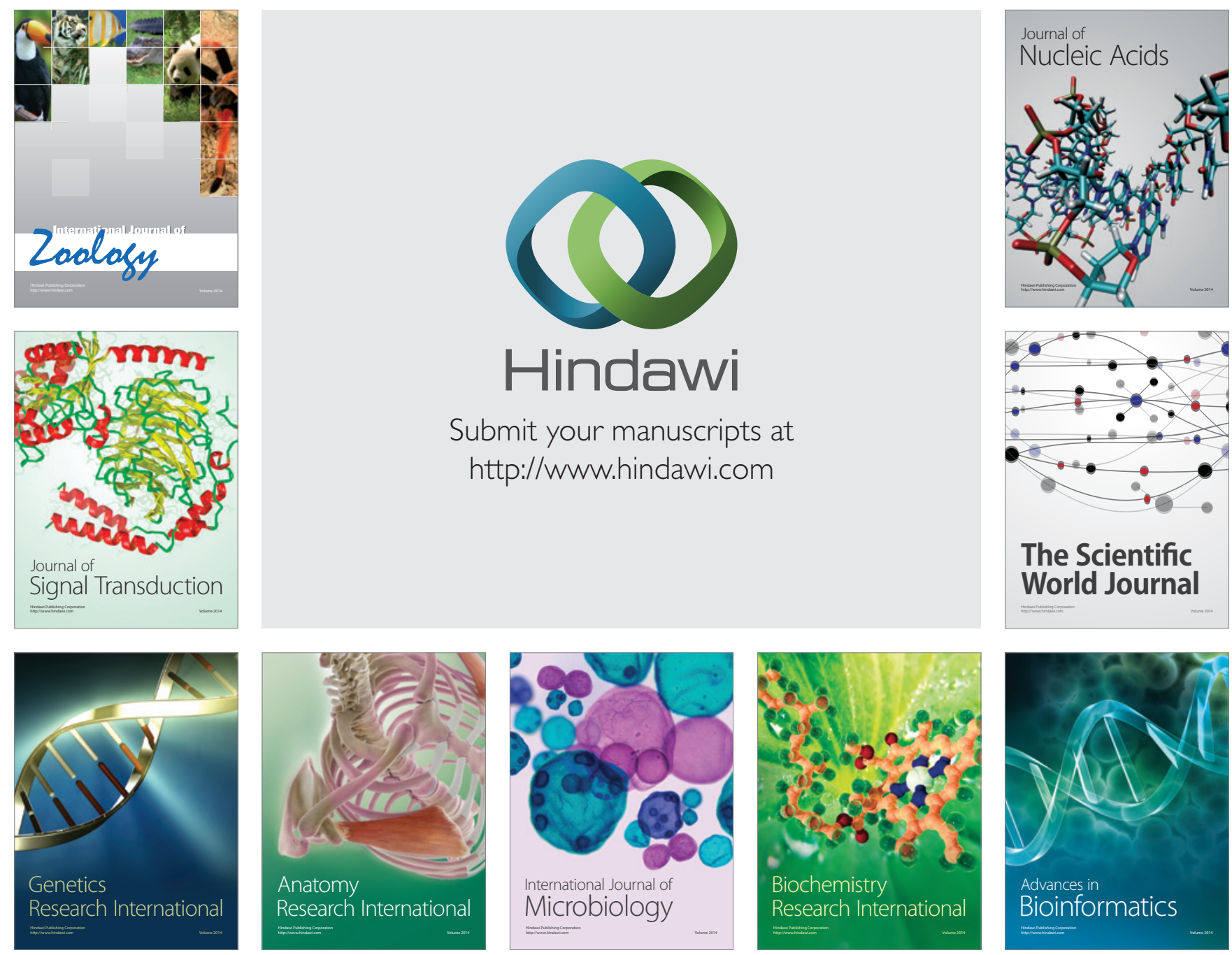

The Scientific World Journal
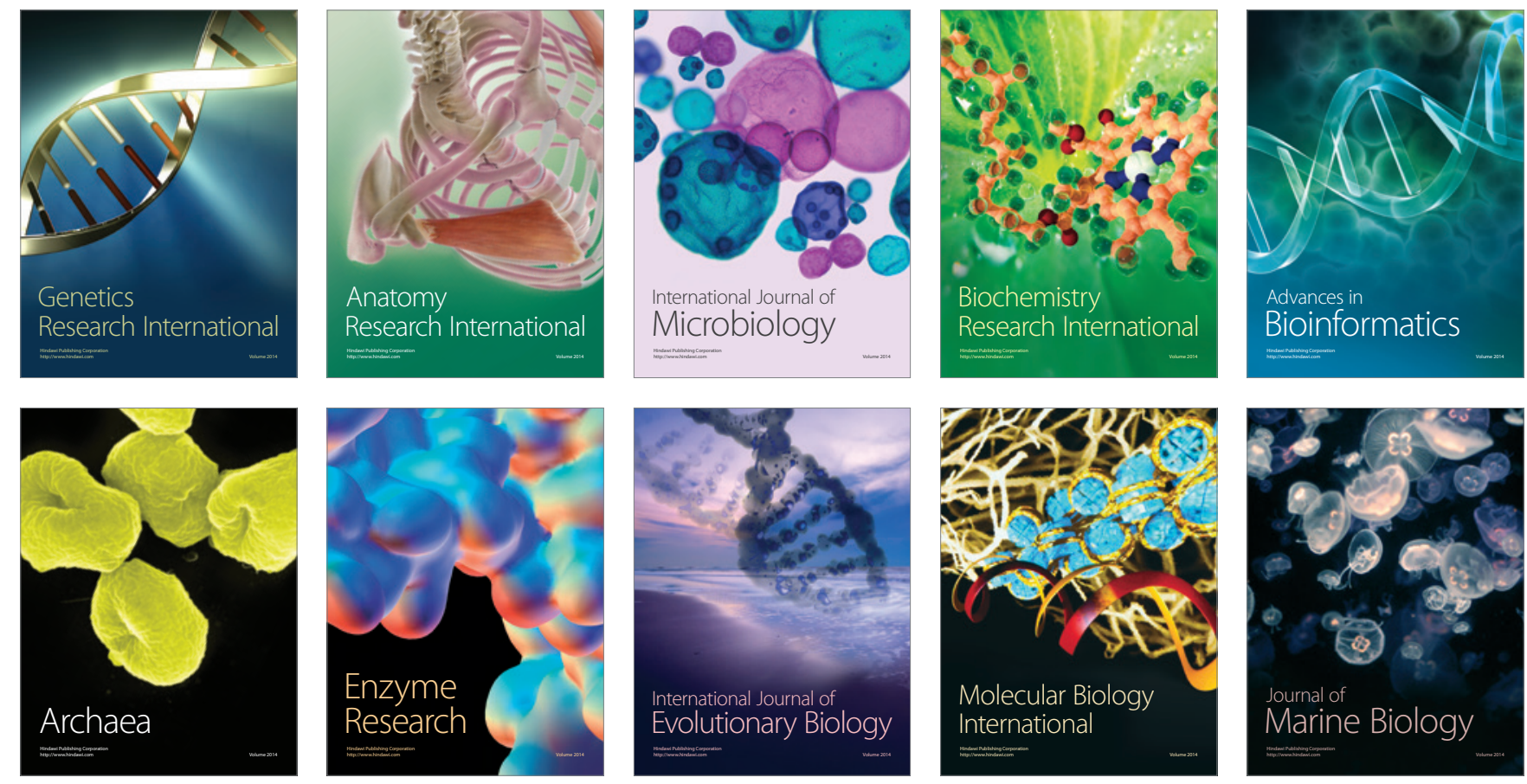